\title{
Comparative Study of Distributed Online Abatement
}

\author{
Raj Haraniya \\ Under Graduate Student \\ Faculty of Technology, \\ Marwadi Education \\ Foundations Group of \\ Institutions, \\ Rajkot, Gujarat, India
}

\author{
Chiranjit Sasmal \\ Under Graduate Student \\ Faculty of Technology, \\ Marwadi Education \\ Foundations Group of \\ Institutions, \\ Rajkot, Gujarat, India
}

\author{
Bipin Bopaliya \\ Under Graduate Student \\ Faculty of Technology, \\ Marwadi Education \\ Foundations Group of \\ Institutions, \\ Rajkot, Gujarat, India
}

\author{
Ashish Revar \\ Asst. Professor, \\ Marwadi Education Foundations Group of Institutions, \\ Rajkot, Gujarat, India
}

\begin{abstract}
Discount or Abatement, this method has been used as one of the best customer attraction policy by the small as well as big companies as it reduces the price on commodity which customer sees as opportunity. Coupon or voucher issued by the shop/companies can be redeemed on the purchasing products for the discount. We think a portal can be made for the advertising of these coupon or discount offers of the products for the customer's cost-effective purpose. The main goal of the portal is to provide an advertisement of all the discounts or coupons of any product at one place for the user's easiness and to improve throughput of the advertisement process. The focus of this paper is on analyzing the advertisement methods and discount or coupon usage by the market.
\end{abstract}

\section{General Terms}

Online shopping, ecommerce, Advertisement, coupon

\section{Keywords}

Discount, Coupon, Advertisement, Market, Customer and Portal.

\section{INTRODUCTION}

\subsection{Discount}

Discounts and allowances are reductions to a basic amount of products or services.There are many purposes for discounting, including; to increase short-term sales, to increase brief-time period income, to move out-of-date inventory, to reward valuable customers, or to encourage distribution channel members to perform a function. Some discounts and allowances are forms of sales income promotion.

\subsubsection{Types of Discount}

Trade Discounts

They are deductions in price given by the wholesaler or manufacturer to the retailer at the list price or catalog price.

\section{Cash Discounts}

They are decreases in value given by the loan boss to the debitor to persuade the debitor to make installment with in determined time.

\section{Seasonal discount}

A price reduction may be offered at certain times of the year when sales would normally be slow.

\section{Order-specific}

A seller may be running a special deal on certain inventory items, or for all items but during a restricted period of time.

\subsection{Coupon}

Coupons are issued by manufacturers of consumer packaged goods or by retailers, for use in retail stores as a part of sales promotions. Coupons can also be targeted selectively to nearby markets in which price competition is great. There are specific uses of coupons which include: to motivating force a purchase, to lessen the value of a specific issue or matters, deliver a unfastened specimen, or to assist permit advertisers better-comprehend the socioeconomics in their consumer.

\subsubsection{Types of Coupons}

Discount Coupons

Discount coupons are as a discount on some fraction or whole price of the item.

\section{Coupon Codes}

Coupon codes are the reference for getting the discount or receiving any voucher or in some shops directly getting offer without any other type of discount vouchers to show. A web merchant will usually have a place for you to enter the coupon code when you add an item to your online shopping basket or proceed to the checkout portion of the situation.

\section{Promotional Codes}

Promotional codes, promotion codes, and promo codes. The only real difference between promo codes and coupon codes is the wording. Promotion codes operate in the same way a coupon code does - enter the code at checkout and you will receive the discount or special offer.

\section{Gift Certificates}

Gift certificate are discount that you can give to someone, only in this case you get to determine the value of that coupon. Like coupons, gift certificates can be for a specific manufacturer, a specific store or a service. They can also be issued by one of the major credit card companies or a bank, in which case it is similar to a debit card.

\section{LITERATURE REVIEW}

\section{AD Basket}

Tarun Bhatia eta. [1] Concluded an idea which provides techniques and methods for the application through which user can store the advertisement like promotion codes, 
coupons and discounts on confrontation by tag data. User can later search or retrieve the advertisement for use over time. On detection of the one or more conditions for usage, can notify user to the potential use through electronic alert. Further from user interaction, the performance of the advertisement can be measure and improve.

\section{COUPONING SYSTEMS AND METHODS}

Shelley B. Tyler eta. [2] suggested that the merchants can create and design own their sub web-pages for advertisement website and provide the coupons or discounts which can redeemed at the shop. These coupons/discounts will have some traceable indicia for the merchant information. In these methods, customer can pay for first half of discount amount on website and later it can be redeemed on the shop location. The website can also limit the discounts for each category on the geographical boundary.

\section{SYSTEM AND METHOD FOR PROVIDING INFORMATION NAVIGATION AND FILTRATION}

Jan Puzicha eta. [3] suggested various methods and techniques for navigation and filtration according to the given user string/terms. User will provide one or more query terms for the filtration and later terms will be relate to the system query terms for the filtering of the search in the system database. By relating with the system query terms, we can rate the user terms and can provide dynamically search results.

\section{METHOD AND SYSTEM FOR CREATING ADVERTISEMENTS ON BEHALF OF ADVERTISERS BY CONSUMER-CREATORS}

Micheal B. Birnholz eta. [4] introduced an innovative method which can attract the customer has been introduced by this patent. A techniques which enables the customer to create the Advertisement for the merchant/shopkeeper on electronic network. These enables customer to upload or create an ad on behalf of advertiser. Advertiser will select or approve the ad which is suitable for their website or shop. Later on, some agreement or bond can be formed between advertiser and customer for the usage of the advertisement. Various methods can be enable to track down the usage of the ad and enable the use of payment scheme according to the relationship brokered.

\section{SYSTEM AND METHOD FOR PROVIDING OPTIMIZED SHOPPING LIST}

John Scott eta. [5] concluded that the online shopping specifically comparing to online price of the product. Ecommerce provides an easy way of accessing information on the Internet to a virtual marketplace. However, these website cannot provide best price automatically for a list of items. According to the present invention, user can input about the shopping list or receive information from the information provider and received information are stored in the database. Received information used to generate a new shopping list and price are compared online to provide an optimized shopping list for new price. The price database includes the information from manually or obtain directly from the electronic form from information provider.

\section{STRUCTURED WEB ADVERTISEMENT}

Sanjay V. Vora eta. [6] Suggested a system which takes some candidate information and based on that information system links that candidate information to some predefined categories. The system can be used to implement a structured advertising system for the World Wide Web. This system a tells relationship between advertising and content provision on the internet. System tracks and monitor searched web pages and by extracting content from that page system decides which advertisement should be place in that web page that is going to serve end user.

\section{ADVERTISING APPLICATION SERVICES SYSTEM AND METHOD}

Christian Cantrell eta. [7] developed a complete automated system for both the advertisers and publishers. In this system publisher provides a system for advertisers with the tools to generate and control an advertising campaign. This system is intended to keep running as one occurrence of the application while supporting multiple publishers.

\section{METHOD AND SYSTEM FOR AUTOMATICALLY CREATING AN IMAGE ADVERTISEMENT}

Wesley Chan eta. [8] suggested a system for generating an electronic document based on the content that is provided by the user. First of all a request for generating an electronic document is received by the server along with the concept. Then after content for the electronic document is suggested by using of concept. And after that an electronic document is generated automatically using the selected content.

\section{INTERNET ADVERTISING - POSTING SYSTEM}

Tsukasa Nagao [9] suggested a system for providing an advertisement with viewer's high interest and publishers a highly effective advertisement. This system is too way system containing two terminal server and viewer. Both are connected each other via network. Viewer are only get advertisement which are pre-registered on the server. Server first of all evaluate the viewers visited advertisement and based on that server decides which ads are going to display in viewer's terminal.

\section{MOBILE COUPON BASKET}

Tarun Bhatia eta. [10] named Mobile Coupon Basket system and that provides techniques and methods for the application through which user can store the advertisement like promotion codes, coupons and discounts on confrontation by tag data. User can later search or retrieve the advertisement for use over time from mobile. On detection of the one or more conditions for usage, can notify user to the potential use through electronic alert like message. Further from user interaction, the performance of the advertisement can be measure and improve. This patent is presented mainly for various handset devices.

\section{SHOPPING LIST MANAGEMENT AND DISCOUNT ORGANIZER}

Nilesh Jain eta. [11] suggested a system that the present patent, some methods and functions are defined to scan a group of coupon with the help of handheld device like mobile which can have transmitter and receiver to store the coupon in the memory. Each coupon is related to a one or more home products and coupons can be categorized according to the expiration dates or discount percentage. After categorization of coupons in the mobile, the information transmitted to the household products for the inventory availability. Further, a query can be executed on the database related to discount or coupon on the product.

\section{ADVERTISING KEYWORD GENERATION USING AN IMAGE SEARCH}

According to Omar Kassem [12] Keywords inputs are important for the search engine and it is one way to target user with proper keywords for the advertisement purpose rather than image. Searching web content based on the image of the product by generating keywords. Advertiser manually add the 
keywords for the advertisement while various methods and techniques can be used to know the keywords for related advertised item by using image as an input. Using image search, information can be retrieve that are similar to image and search results can include various URLs and keywords from other campaigns. Keyword-suggesting device can determine the results and list of keywords are suggested related to data.

\section{FACILITATING CLIENT-SIDE MANAGEMENT OF ONLINE ADVERTISING INFORMATION, SUCH AS ADVERTISING ACCOUNT INFORMATION}

Elan Dekel eta. [13] developed a system that provides a way for the client-side management of application which permits advertisers and/or service representatives to simply and with efficiency view, navigate, and edit ad accounts, with large numbers of campaigns, ad groups, keywords and ad creatives by a tab choice. The customer can later find the useful information from the results for the beneficial usage.

\section{SYSTEM AND METHOD FOR LOCATING REWARDS AND DISCOUNTS IN E-COMMERCE}

Alex Mashinsky [14] suggested an idea that provides system and methods for the customers who purchase item over the internet to locate and take advantage of special rates or discount to the special group of user under condition. User can also create and maintain his/her wish-list on the website with account. Further, the system can match the condition of buyer and seller for the product to give promotional rates. The system provides a method to obtaining desired item or services to the buyers by requesting same to the seller. Vendors or sellers can directly discount to the user and by these manner of knowledge mining capabilities helpful for sellers. The system can also monitor the records and various rewards can present to the buyers from seller with specific circumstances.

\section{EARLY-PAYMENT DISCOUNT FOR E-BILLING SYSTEM}

Elaine Scott Mason [15] developed An Early Payment Discount (EPD) mechanism that enables customers to automatically receive an early payment discount for paying electronically like electronic fund transfer. The discounted/cut price supplied via business cooperation solely based on the present day E-invoice and discount is robotically calculated relies upon on the number of days closing to the authentic length time. Before making the invoice available to the user, the third party informs audit department of the request and checked/reviewed. The audit department approves/rejects the invoice and conforms the originality of invoice paper while third party informed for the same.

\section{COMPARATIVE STUDY OF EXISTING SYSTEM}

Attracting new customers and then retaining them is critical for the success of e-commerce. Customer beliefs that on-line/a web /an internet merchant (e-vendor) are often trustworthy play an important role in each attracting new online customers and later in holding existing ones.

Trust is crucial in on-line/a web/a web atmosphere because of the larger ease with that online clients, as compared with bricks-and-mortar save clients, is taken advantage of in a web community, even while not their facts/data.

E-commerce Business is growing nowadays at flying rate by lower price $9-15 \%$ on internet than prices in conventional outlets, depending on whether taxes, shipping, and shopping costs are included in the price. So, what lies ahead is digital marketing world in which trust plays the vital role and website/portal for these should have a required/specific information for the best customer experience and usage.

However, once we check these costs by proxies for market share, we discover dispersion is lower in web channels/Ecommerce site than in typical channels/website, reflective the dominance of sure heavily branded retailers. People are mostly looking for branded items with less prices or discount and they mainly like portal which can provide them required result on the way i.e. anywhere and anytime.

Table 1.1 Comparison with existing system

\begin{tabular}{|l|l|l|l|l|}
\hline & $\begin{array}{l}\text { Merchant } \\
\text { Circle } \\
{[17]}\end{array}$ & $\begin{array}{l}\text { Ad } \\
\text { Magnet } \\
{[18]}\end{array}$ & $\begin{array}{l}\text { Chitika } \\
{[19]}\end{array}$ & $\begin{array}{l}\text { Propose } \\
\text { system - } \\
\text { Discoun } \\
\text { tWale }\end{array}$ \\
\hline $\begin{array}{l}\text { Itself a } \\
\text { publisher }\end{array}$ & $\mathbf{x}$ & $\mathbf{x}$ & $\mathbf{x}$ & $\checkmark$ \\
\hline $\begin{array}{l}\text { Coupon } \\
\text { Generation }\end{array}$ & $\mathbf{x}$ & $\mathbf{x}$ & $\mathbf{x}$ & $\checkmark$ \\
\hline $\begin{array}{l}\text { Coupon } \\
\text { Redemption }\end{array}$ & $\mathbf{x}$ & $\mathbf{x}$ & $\mathbf{x}$ & $\checkmark$ \\
\hline $\begin{array}{l}\text { Free of cost } \\
\text { for every } \\
\text { user and } \\
\text { shop-keeper }\end{array}$ & $\mathbf{x}$ & $\checkmark$ & $\mathbf{x}$ & $\checkmark$ \\
\hline $\begin{array}{l}\text { User } \\
\text { Management }\end{array}$ & $\mathbf{x}$ & $\mathbf{x}$ & $\mathbf{x}$ & $\checkmark$ \\
\hline
\end{tabular}

Current system like Ad magnet [10] and Merchant Circle [11] have many limitations. They only provide ads containing only details about shops and address. Our proposed system DiscountWale will provide full information about local shops containing all details and product information additionally this system will also provide latest discount and coupons which are currently running in that shops. So basically person can get high-quality deals among all of the similar shops and also can generate plus redeem coupon which is not provided with the aid of different comparable website. This system also implements structured web advertisement [6] which is very specific to individual user.

DiscountWale portal runs in the two modes: shopkeeper and user. In Shopkeeper mode, shopkeeper can publish their advertisement and manage them as required. Shopkeepers can generate discount coupons, distribute them as per offers, gets feedback for product and offers. In User mode, it helps the user to find the offers easily as well as easy navigation to the shop. User can filter ads based on the offer, area wise, amount and so on.

DiscountWale mainly focus on advertising discounted product only and free of cost for shopkeeper. It helps later on like digital marketing of shopkeeper offline shops. User management will shopkeeper to understand what user wants in what prices and etc. by user feedbacks. 


\section{CONCLUSION}

From related study about the discount and coupon, we can provide/make a portal in which all discount and coupon will be displayed at one place for user easiness. User can store and retrieve the advertisement from their account, whenever they want and can manage it. Portal should also provide functionality of coupon or voucher redemption for user, which ever shop allows. Portal should also notify user for the expiry date and time as well as it should also optimize the shopping list of user by comparing online price for the items. Thus, we can make a portal which can provide these different functionality for user friendly system and to make better use of advertisement.

\section{REFERENCES}

[1] Tarun Bhatia, Abhay Gupta, Eric Bax, "AD BASKET”, US 20120265608A1,Oct.18, 2012.

[2] Shelley B. Tyler, Paul SybroWsky, Lynne SybroWsky,"COUPONIN SYSTEMS AND METHODS”, US 20130041740A1,Feb.14,2013.

[3] Jan Puzicha, Thomas Hofmann, "SYSTEM AND METHODS FOR PROVIDING INFORMATION NAVIGATION AND FILTRATION",US007657522B1, Feb.2,2010

[4] Micheal B. Birnholz, Scott P. Weiner, Jeff Roschman, "METHOD AND SYSTEM FOR CREATING ADVERTISEMENTS ON BEHALF OF ADVERTISERS BY CONSUMER-CREATORS", US 20080140502A1, Jun.12,2008.

[5] John Scott, Paul Davis, "SYSTEM AND METHOD FOR PROVIDING OPTIMIZED SHOPPING LIST”,US007726563B2,Jun.1,2010

[6] Sanjay V. Vora, Joseph R. Kluck, William J. Nerenberg, David E.,"STRUCTURED WEB ADVERTISEMENT”,US7493553B1,Feb.17,2009.

[7] Christian Cantrell, Mark Helmstetter. Benjamin Simon, Patrick Transue, "ADVERTISING APPLICATION SERVICES SYSTEM AND METHOD”,US20020194215A1, Dec 192002.

[8] Wesley Chan, Sumit Agarwal, Rama Ranganath, Leora Ruth, Wiseman Deepak Jindal, "METHOD AND SYSTEM FOR AUTOMATICALLY CREATING AN
IMAGE ADVERTISEMENT”, US7996753 , Aug 09 2011

[9] Tsukasa Nagao, "INTERNET ADVERTISING POSTING SYSTEM”, US20110015977A1, Jan 202011.

[10] Tarun Bhatia, Abhay Gupta, Eric Bax,"Mobile Coupon Basket", US20120265605, Oct. 18, 2012.

[11] Nilesh Jain, Padmashree K., Omesh Tickoo, , "SHOPPING LIST MANAGEMENT AND DISCOUNT ORGANIZER”, US20090307080A1, Dec. 10, 2009.

[12] Omar Kassem "ADVERTISING KEYWORD GENERATION USING AN IMAGE SEARCH”, US 20130124303 A1, May 16, 2013.

[13] Elan Dekel, Darren Delaye, Matthew Hiller, Art Komninos, Igor Tandetnik, Alan Warren, "FACILITATING CLIENT-SIDE MANAGEMENT OF ONLINE ADVERTISING INFORMATION, SUCH AS ADVERTISING ACCOUNT INFORMATION", US 200701741 18Al, Jul. 26, 2007.

[14] Alex Mashinsky, "SYSTEM AND METHOD FOR LOCATING REWARDS AND DISCOUNTS IN ECOMMERCE.”, US 2009/0030789 A1, Jan. 29, 2009.

[15] Elaine Scott Mason, "EARLY-PAYMENT DISCOUNT FOR E-BILLING SYSTEM”, US008121894B2, Feb. 21, 2012.

[16] D. Gefen, E. Karahanna, D. W. Straub, "Inexperience and experience with online stores: the importance of TAM and trust", INSPEC Accession Number: 7765992, DOI: 10.1109/TEM.2003.817277, 14 October 2003.

[17] (Deals, Quotes, Coupons, Advice from Local Merchants - MerchantCircle.com).

[18] (Ad Magnet | Largest Indian Online Ad Network www.admagnet.net)

[19] (Chitika | Online Advertising Network www.chitika.com, n.d.)

[20] Role of Coupons in Retail Marketing - Management Study Guide www.managementstudyguide.com/role-ofcoupons-in-retail-marketing.htm 